\title{
A Competency Model for Traditional Chinese Medicine Practitioners: A Cross-Sectional Study in China
}

\author{
Yilin Chen
}

\begin{abstract}
Since the Traditional Chinese Medicine (TCM) has became increasing popular in mainland China, how to improve the TCM practitioners medical service became a research subject. To develop a competency model would benefit the TCM practitioners and help the management of TCM hospitals or TCM sections in general hospitals. We generated 27 items to form questionnaire and 908 valid responses were identified. After data processing, we notify that professional ethics, self-progress, professional basis, TCM knowledge/skills and modern medical knowledge/skills are the key factors for TCM practitioners' competency. This competency model is on count of mainland China's TCM practitioners, it could have reference value for countries and regions other than China, but it would not be complete application outside China. However, our competency model has many practical implications, it would be helpful for the hospital administrators to use this model to develop the adjustment managing measures.
\end{abstract}

Index Terms-Competency model, TCM practitioner. crosssection.

\section{INTRODUCTION}

Over the past 10 years, there has been a significant development in China, Traditional Chinese medicine as one of the most irreplaceable categories of Chinese traditional culture become well-known all over the world. Historically, Chinese medical has already accompanied the rise and fall of China. Recently, with those changing, the requirement of Chinese medical doctor has improved time by time. Traditional Chinese Medicine knowledge and skill, professional ethics, modern medical knowledge and skills, clinical practice, and communication skills, as the basic standard to be judged as a good doctor. Assessments are then targeted to the competencies to determine when individual doctor achievement is sufficient.

With the development of Chinese economy, the Traditional Chinese Medicine (TCM) is now become increasing popular with the Chinese middle class, for its green noninvasive therapy, for example, Tuina, Acupunture, etc.. Hsu(2008) [1] The investigation shows that, in mainland China, the TCM outpatient service was up to $15.7 \%$ of total Chinese medical service, and more than $53 \%$ of Chinese citizens chose the TCM as their alternative medical therapy in 2015. Cao (2004) [2] As the demand of medical market is more and more vigorous, the TCM practitioner's competency were widely concerned by most Chinese people, because of the pursuit of high-quality medical demand. Therefore, to develop a TCM practitioners competency model which suits the mainland China's physical truth become necessary. The TCM practitioner's competency model would give great enhancement for the Chinese medical hospital management and improve the quality of Chinese medical service.

The Competency idea was proposed by McClelland in 1973, which was regard as a main method to judge the professional ability of individuals or groups. McClelland (1973) [3] Competency models is important due to the requirements for the agencies to evaluate the employees. Competency models provide managers professional, efficient, expert employees in the process of creating the better workforce. Binder, Neureiter, \& Lastro (2019) [4] There are two parallel medical systems in mainland China, one is the Western medicine that occupied the main role for the medical service, the other one is the TCM that plays a complementary medicine role. For the western medical practitioners, scholars had already developed the competency models, with information and management, professionalism, clinical skills and patient care, interpersonal communication, and health promotion \& disease prevention, master of medical knowledge, academic research, teamwork dimensions. Zhuang Liu (2016) [5]

However, Western medicine treats problems in the biological body by focusing on symptoms, and using chemicals and surgery to decrease those symptoms. Chinese medical knowledge is different from Western, instead of the formation of new chemistry, doctors believed the human body as a whole which connect to five elements in the world: gold, wood, water, fire, and soil. These five elements all connects to each other, and what happen with one will influence the others. Lei \& Shijie (2009) [6] According to Zhang (2010) "It has its own unique theories for treating disease and to enhance health. There are many modalities included in TCM, such as Chinese herbal medicine, moxibustion, acupuncture, or Tuina." Meijun, Zhicheng, Bin, Wei, \& Jianwei (2016) [7] Several researchers gave their own definition about the competency model, for instance, Parkinson and Chew try to define the professional competency as knowledge, ethics and independent judgement; Parkinson \& Chew (2016) [8] Wendy argued that the competency model was an ability that can fulfill the organizational demand. Wendy \& Strebler (1994) [9] some scholars regarded competency model as individuals knowledge, skill and attitude, etc. Kirby, Crawford, Smith, Thompson, \& Sargeant (2011) [10] There are plenty of research about the competency and its model, how to development a Chinese national wide TCM practitioners' 
model become necessary and feasible.

TABLE I: RESULTS OF EXPLORATORY FACTOR ANALYSIS

\begin{tabular}{|c|c|c|c|}
\hline Items & I & II & III \\
\hline A01. No matter the patient is poor or rich, I will treat she/he equally. & .815 & .211 & .001 \\
\hline A02. I can help patients build confidence in rehabilitation based on medical knowledge. & .788 & .275 & .100 \\
\hline A03. I abide by the relevant national law and regulations in the course of medical treatment. & .766 & .150 & .201 \\
\hline A04. For some difficult cases out of my ability, I would not vouch for the success of treatment. & .760 & .139 & .133 \\
\hline A05. I show kindness and friendliness in the course of medical treatment. & .738 & .166 & .292 \\
\hline A06. I had a clinical study of a particular disease. & .085 & .786 & .164 \\
\hline A07. I make full use of the various learning resources from the hospital and the network to improve myself. & .161 & .745 & .244 \\
\hline A08. I have a good understanding of medical insurance, medical management and other related regulations. & .174 & .728 & .225 \\
\hline A09. I have thought about a particular disease and search for related treatments for future reference. & .417 & .661 & .165 \\
\hline A10. I am actively involved in medical team work such as consultation, group meeting, training, and so on. & .437 & .620 & .165 \\
\hline A11. I pay attention to the practical application of TCM theory in clinic. (EXCLUDED) & .419 & .435 & .326 \\
\hline A12. I understand the information of common diseases and epidemics in the professional field. & .172 & .165 & .799 \\
\hline A13. I have a solid medical theoretical foundation, both in modern medicine and traditional Chinese medicine. & .044 & .397 & .767 \\
\hline $\begin{array}{l}\text { A14. When encountering difficult cases, I would try to use my own judgment to analyze and find out the relevant } \\
\text { information. }\end{array}$ & .263 & .207 & .762 \\
\hline
\end{tabular}

B01. Internal traditional Chinese medicine. $\quad \begin{array}{cc}.257\end{array}$

$\begin{array}{lll}\text { B02. Basic theory of traditional Chinese medicine. } & \mathbf{. 8 2 5} & .270\end{array}$

$\begin{array}{lrl}\text { B03. Traditional Chinese pharmacy. } & \mathbf{. 7 9 9} & .297\end{array}$

B04. Four diagnostic examinations of TCM, i.e., inspection, listening and smelling, inquiry, and palpation. $\quad .791 \quad .290$

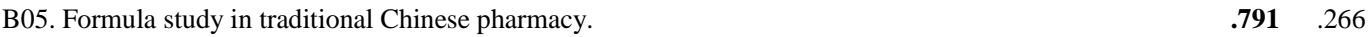

$\begin{array}{lll}\text { B06. The concept of holism and syndrome differentiation of traditional Chinese medicine. } & \mathbf{. 7 1 8} & .379\end{array}$

B07. The occurrence, development and prognosis of clinical acute and chronic diseases. $\quad .266 \quad \mathbf{. 8 3 3}$

B08. The mechanism, use, and clinical effect of common drugs. $\quad .247 \quad \mathbf{. 8 0 4}$

B09. Using medical reports and images to develop a basic treatment plan. $\quad .230 \quad \mathbf{. 8 0 1}$

$\begin{array}{ll}\text { B10. Evidence-based thought of modern medicine. } & .314 \quad \mathbf{. 7 7 3}\end{array}$

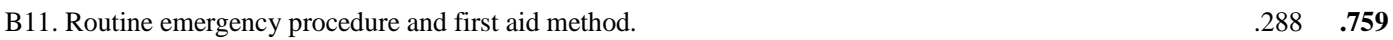

B12. Diagnosis process in modern medicine. $\quad \begin{array}{ll}430 & \mathbf{. 7 3 4}\end{array}$

B13. Observation and physical examination of human body. (EXCLUDED) $\quad .538 \quad .561$

Note: Item A11 and Item B13 were excluded after EFA. Factor I V were named as professional ethics, self-progress, professional basis, TCM knowledge/skills, and modern medical knowledge/skills. (N=453)

\section{METHODS}

In order to build a competency model for TCM practitioners, we followed the protocol of developing measurement according to previous literature (e.g. Churchill Jr., 1979 [11] ; Hinkin, 1998 [12]).

As the first step, we reviewed previous literature, generated the initial item pool and did filtering. We select items which are related to TCM practitioners' competency from previous literature (e.g., Feng, Han, Lai, Wang, \& Liu, 2017 [13]; Zheng, Sun, \& Wang, 2019 [14]). Then we invited 5 TCM doctors to evaluate these items concerning the relevance and importance to the main theme.

27 items were finally generated. Among them, 14 items 
described behaviors of TCM practitioners, while the other 13 items describing knowledge or skills for TCM practitioners. Given that the two parts have different ways in expression, they were in the distinguished two sections of the questionnaire. For items related to behaviors, a 5-point Likert format was adopted, ranging from $1=$ strongly disagree to $5=$ strongly agree. For items related to knowledge or skills, we used a 4-point response format, ranging from 1=barely mastered to $4=$ extremely mastered.

Then, we administrated a survey with the help of some TCM doctors to collect data. The questionnaire was distributed to the TCM practitioners who work at TCM hospitals or TCM sections of general hospitals located in Beijing, Tianjing and Guandong Province. 908 valid responses were identified, yielding a validation rate at $89.6 \%$. The average age was 38.6 years $(\mathrm{SD}=9.2)$. Among them, $25.7 \%$ had the title of resident doctor, $36.0 \%$ were attending doctors (doctor-in-charge), $21.6 \%$ were associate chief doctors (associate professor), and $19.6 \%$ had the title of chief doctor (professor).

We separated the valid responses into two part for analysis. The first half was used for exploratory factor analysis (EFA), thus the initial factor structure could be developed. We adopted principle factor analysis to extract factors and varimax approach to rotate. In this process, we would exclude some items by the criteria that a) the factor loading of an item is less than .50 ; b) the cross-loading of an item is greater than .45. Internal consistency (i.e., Cronbach's alpha) would also be estimated for each factor to ensure the reliability of the measurement.

The second half was used for confirmative factor analysis (CFA), thus the initial structure could be validated. The indices to examine model fit in CFA were chi-square $\left(X^{2}\right)$, degree of freedom $(d f)$, comparative fit index $(C F I)$ and root mean square error of approximation (RMSEA). In addition, we also computed the composite reliability for each factor according to previous scholars (Bacon, Sauer, \& Young, 1995 [15]; Nunnally, 1978 [16]).

\section{RESULTS}

Considering the expression style were different for14 items in section I and 13 items in section II, we ran EFA separately. KMO coefficients for section I and section II was .899 and .930 , respectively, and Bartlett's test of sphericity were both significant, indicating the adequacy to run factor analysis. Three factors for section I and two factors for section II were emerged, concerning the eigenvalue criterion. According the criteria mentioned before, two items were excluded. Table I demonstrates the result of EFA, showing the factor loading of each item.

Factor I refers to moral or ethical behaviors in the work of TCM practitioners, thus we termed it professional ethics. Factor I has five items. Factor II consists of five items, which describing various behaviors to improve oneself as a doctor, thus termed as self-progress. Factor III, termed professional basis, which are basic abilities to be a doctor, include three items. Factor IV consists of six items, which was related to key TCM knowledge and skills, thus termed TCM knowledge/skill. Factor $\mathrm{V}$ contains important medical knowledge and skills in modern medicine and has six items, thus we termed it modern medical knowledge skills.

The Cronbach's alpha coefficients of the five factors are $.873, .837, .788, .922$ and .916 , respectively. The overall Cronbach's alpha coefficient is .942 . These data suggested this research has a good reliability.

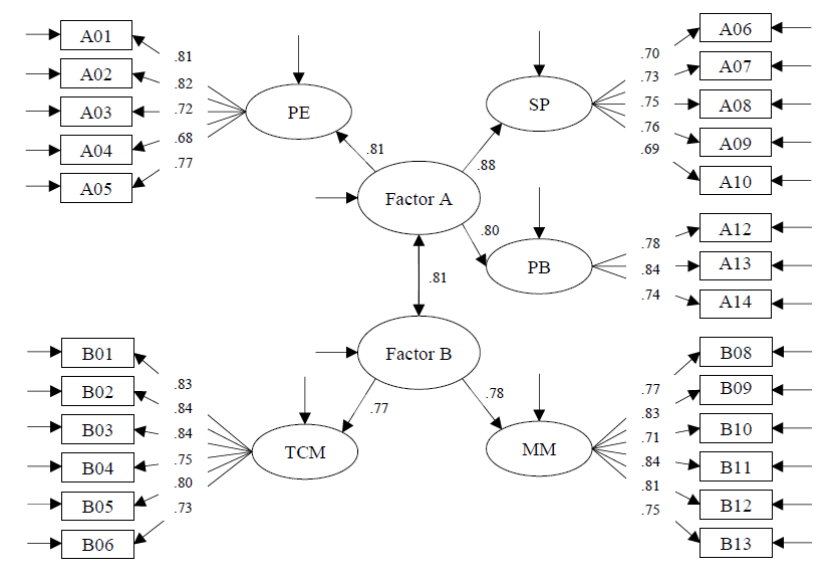

Fig. 1. Result of confirmative factor analysis.

Note: $\mathrm{PE}=$ professional ethics $; \mathrm{SP}=$ self-progress $; \mathrm{CP}=$ professional basis; $\mathrm{TCM}=$ TCM knowledge/skills; $\mathrm{MM}=$ modern medical knowledge/skills; the numbers on the paths were the weights calculated from data of the survey $(\mathrm{N}=455)$.

After we developed the initial structure of the competency model of TCM practitioners by EFA, we need verify it by CFA. We construct a three-order model as Figure 1 shows. All items belong to five factors; professional ethics, selfprogress, and professional basis belong to Factor A, while TCM knowledge/skills and modern medical knowledge/skills belong to Factor B; Factor A correlate with Factor B. The indices of CFA suggested this model fit the current sample well $\quad\left(X^{2}=1000.2, \quad d f=81, \quad X^{2} / d f=3.72, \quad C F I=.898\right.$, RMSEA=.077).

In comparison, we also developed alternative models: 1) a two-order model in which five factors belong to one secondorder main factor $\left(X^{2}=1033.1, d f=80, X^{2} / d f=3.83, C F I=.893\right.$, RMSEA=.079); 2) combine professional ethics and selfprogress together, others remains the same $\left(X^{2}=1207.6\right.$, $\left.d f=80, X^{2} / d f=4.47, C F I=.869, R M S E A=.087\right)$; 3) combine self-progress and professional basis together, others remains the same $\left(X^{2}=1217.5 \quad d f=80, \quad X^{2} / d f=4.51, \quad C F I=.868\right.$, RMSEA=.088); 4) combine TCM knowledge/skills and modern medical knowledge/skill together, others remains the same $\quad\left(X^{2}=1806.5 \quad d f=79, \quad X^{2} / d f=6.66, \quad C F I=.785\right.$, $R M S E A=.112)$; 5) all items belong to one main factor $\left(X^{2}=3172.0, \quad d f=75, \quad X^{2} / d f=11.53, \quad C F I=.595\right.$, $R M S E A=.152)$. The result indicated that our hypothetical model was the best model.

The composite reliability for the five factors were $.873, .846, .829, .913$ and .906 , respectively, which were all above .700 . All the indices were greater than the criteria suggested by previous scholars, thus this scale was reliable.

All the results provided evidences for the reliability and validity of this measurement.

\section{Discussions}

Base on the data collection, we developed the Traditional 
Chinese Medicine practitioners' competency model, which include five aspects, professional ethics, self-progress, professional basis, TCM knowledge/skills and modern medical knowledge/skills. This is a cross-sectional study, we conducted the questionnaire through different areas of China, given that China is a vast and diversified country, focusing on only one region may cause the competency model incomplete and inaccurate. In another word, this competency model is suitable for most Chinese medicine hospitals or TCM sections in general hospitals. Compared with the previous research, for example, the research capacity of TCM practitioners, Yan \& Ni (2012) [17], or the education and training of TCM practitioners in higher education institute, Sherer et al. (2016) [18], our model is more comprehensive and practical.

Our competency model of TCM practitioners has many practical implications, it would be helpful for the hospital administrators to use this model to develop the adjustment managing measures, and it may also help to revise the teaching curricular in TCM training and education institute. However, this competency model is on count of mainland China's TCM practitioners, it could have reference value for countries and regions other than China, but it would not be complete application outside China. Furthermore, to test future applications and effects in TCM hospitals and TCM sections in general hospitals would be a further research choice.

\section{REFERENCES}

[1] E. Hsu, "The history of chinese medicine in the people's republic of china and its globalization," East Asian Science, Technology and Society, vol. 2, no. 4, pp. 465-484, 2008.

[2] H. Cao, Basic Theory of Traditional Chinese Medicine, Beijing: China TCM Press, 2004.

[3] D. C. McClelland, "Testing for competence rather than for "intelligence," American Psychologist, vol. 28, no. 1, pp. 1-14, 1973.

[4] C. Binder, C. Neureiter, and G. Lastro, "Towards a model-driven architecture process for developing industry 4.0 applications," International Journal of Modelling and Optimization, vol. 9, no. 1, 2019.

[5] Z. Liu et al., A Competency Model for Clinical Physicians in China: A Cross- Sectional Survey, Plos One, 2016.

[6] L. Lei and C. Shijie, "On the research progress of education of traditional chinese medicine," Journal of Traditional Medicine Management, vol. 17, no. 10, pp. 894-899, 2009.

[7] L. Meijun, L. Zhicheng, X. Bin, Z. Wei, and C. Jianwei, "Review of systematic reviews and Meta-analyses investigating traditional chinese medicine treatment for type 2 diabetes mellitus," Journal of Traditional Chinese Medicine, vol. 36, no. 5, pp. 555-563, 2016.
[8] A. Parkinson and L. Chew, "An analysis of applied professional teaching practices in relation to research and policy," The Business and Management Review, vol.7, no. 3, pp. 317-325, 2016.

[9] H. Wendy and M. Strebler, "Defining managerial skill and competences," Gower Handbook of Management Development, PP. 79-96, 1994.

[10] R. L. Kirby, K. A. Crawford, C. Smith, K. J. Thompson, and J. M. Sargeant, "A wheelchair workshop for medical students improves knowledge and skills," American Journal of Physician, vol. 90, no. 3, pp. 197-206, 2011.

[11] G. A. Churchill, "A paradigm for developing better measures of marketing constructs," Journal of Marketing Research, vol. 16, no. 1, pp. 64-73, 1979 .

[12] T. R. Hinkin, "A brief tutorial on the development of measures for use in survey questionnaires," Organizational Research Methods, vol. 1, pp. 104-121, 1998.

[13] S. Feng, M. Han, L. Lai, S. Wang, and J. Liu, "Research capacity at traditional Chinese medicine (TCM) centers in China: A survey of clinical investigators," Evidence-Based Complementary and Alternative Medicine, pp. 1-8, 2017.

[14] B. Zheng, G. Sun, and H. Wang, "Evaluation tool for traditional Chinese medicine students: A competency perspective," Sage Open, 2019.

[15] D. R. Bacon, P. L. Sauer, and M. Young, "Composite reliability in structural equations modeling," Educational and Psychological Measurement, vol. 55, no. 3, pp. 394-406, 1995.

[16] J. C. Nunnally, Psychometric Theory, (2 ed.). New York: McGrawHill, 1978.

[17] X. Yan and Q. Ni, "Innovation research on the operational mechanism of TCM standardization work of China association of TCM," Clinical Journal of Chinese Medicine, vol. 16, no. 4, pp. 1-3, 2012.

[18] R. Sherer, H. Dong, F. Yu, J. Fan, J. Li, I. Jiang, and X. Yu, “A survey of graduates' perceptions on a Chinese medical school's traditional and reform curricula.," Perspectives on Medical Education, vol. 5, no. 4, 2016.

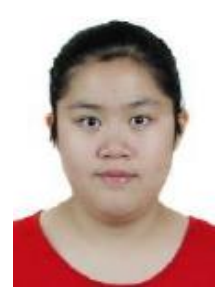

Yilin Chen was born in Beijing, China. She is currently a junior student of Westside Christian High School (Tigard, Oregon).

She is interested in research in education field, especially research of Chinese Education and Western Education System. She also spends fairly amount of time researching on competency models of Human Resources.

Her article Beauty in Each Flower, Wisdom in Each Student and Justice were published at English on Campus; The Importance of the Family and the Community in A Long Way Gone will be published at Speed Reading. 